\title{
Diz Osteoartritli Hastalarda Artroskopik Debridman Sonrası Eklemiçi Hyaluronik Asitle Birlikte Peroral E Vitamini Tedavisinin Etkinliği: Prospektif, Randomize, Kontrollü Çalıșma \\ The Efficacy of Intra-Articular Injection of Hyaluronic Acid With Supplemental Peroral Vitamin E Following Arthroscopic Debridement in the Treatment of Knee Osteoarthritis: A Prospective, Randomized, Controlled Study
}

\author{
Ahmet ASLAN, Vecihi KIRDEMIR*, Tolga ATAY* Yakup Barbaros BAYKAL*, Özgür AYTEKIN**, Fazıl Cüneyt AYDOĞAN*** \\ Dr. Münif Islamoğlu Kastamonu Devlet Hastanesi, Ortopedi ve Travmatoloji Kliniği, Kastamonu, Türkiye \\ * Süleyman Demirel Üniversitesi Tıp Fakültesi, Ortopedi ve Travmatoloji Anabilim Dalı, Isparta, Türkiye \\ **Çorum Devlet Hastanesi, Ortopedi ve Travmatoloji Kliniği, Çorum, Türkiye \\ ***Nevşehir Devlet Hastanesi, Ortopedi ve Travmatoloji Kliniği, Nevşehir, Türkiye
}

\section{Özet}

Amaç: Bu çalışmada; konservatif tedaviyle semptomları iyileşmeyen diz osteoartritli hastalarda artroskopik debridman ve sonrasında eklem içi hyaluronik asit ile birlikte peroral $\mathrm{E}$ vitamini tedavisinin klinik sonuçlarınının etkili olup-olmadığını değerlendirmeyi amaçladık.

Gereç ve Yöntem: Amerikan Romatoloji Koleji kriterlerine göre osteoartrit tanısı konulan, toplam 44 hasta, artroskopik debridman sonrası rastgele 3 gruba ayrıldı. Birinci gruba (S) eklem içi hylan G-F 20 uygulandı. Ikinci gruba (S+E) eklem içi hylan G-F 20 ile birlikte peroral vitamin E verildi. Üçüncü gruba (K) sadece artroskopik debridman uygulandı. Ağrı, sertlik ve fonksionel kapasite skorları; ameliyat öncesi, ameliyat sonrası 6 . ve 12 . aylarda Western Ontario ve McMaster Üniversiteleri Osteoartrit Indeksi (WOMAC) ile belirlendi.

Bulgular: Bütün gruplarda, ameliyat öncesi WOMAC skoruyla karşılaştırıldığında ameliyat sonrası 6 . ve 12 . aydaki skorlar azalmıştı. S+E ve S grubunda ameliyat sonrası hem 0-6. ay hem de sonrası 6-12. ay WOMAC skorundaki fark kontrol grubuna göre anlamlıydı $(p<0,05)$. Semptomları azaltmada $S+E$ grubunun $S$ grubuna göre ameliyat sonrası 6-12. aylarda daha iyi olduğu bulundu $(p<0,05)$.

Sonuç: Diz osteoartritli olgularda uygun endikasyonlarda artroskopik debridmanın yararlı olduğunu, sonrasında eklem içi hyaluronik asit ve oral $\mathrm{E}$ vitamini tedavisinin osteoartritin semptomlarının hafifletilmesinde etkili olabileceği kanısındayız. Türk Fiz Tıp Rehab Derg 2012;58:199-203.

Anahtar Kelimeler: Artroskopik debridman; diz osteoartriti; hylan G-F 20; eklem içi hyaluronik asit; E vitamini

\section{Summary}

Objective: We evaluated clinical results of intra-articular injection of hyaluronic acid and peroral Vitamin E treatment after arthroscopic debridement in patients with knee osteoarthritis who got no cure with medical treatment previously. Materials and Methods: A total of 44 patients with knee pain, who were diagnosed as having knee osteoarthritis according to the American College of Rheumatology criteria, were included in this study. The subjects were randomly divided into 3 groups after arthroscopic debridement: Group S was given intra-articular Hylan G-F 20 treatment; Group S+E - intraarticular Hylan G-F 20 treatment plus oral vitamin E; and Group C underwent only arthroscopic debridement. Pain, stiffness and functional capacity scores were evaluated preoperatively and 6 and 12 months postoperatively according to the Western Ontario and McMaster Universities Osteoarthritis Index (WOMAC).

Results: In all groups, 6- and 12-month postoperative WOMAC scores were lesser than the preoperative ones. The WOMAC scores at 6 and 12 months were statistically lower in the $S+E$ and $S$ groups than in the group $C(p<0.05)$. The $S+E$ group demonstrated better results in terms of improvement in symptoms than the S-group at 6 and 12 months postoperatively $(p<0.05)$.

Conclusion: We believe that arthroscopic debridement is beneficial in suitable knee osteoarthritis cases and vitamin $\mathrm{E}$ and intra-articular hyaluronic acid may reduce the symptoms of knee osteoarthritis. Turk J Phys Med Rehab 2012;58:199-203.

Key Words: Arthroscopic debridement; knee osteoarthritis; hylan G-F 20; intra-articular hyaluronic acid; vitamin $\mathrm{E}$ 


\section{Giriş}

Osteoartrit (OA) patolojik olarak; sinovya ve eklem kıkırdağında fokal bozulma, subkondral kemikte kist, skleroz, osteofit oluşumu ve ilgili tüm eklem yapılarında değişikliklerle karakterizedir. Ayrıca sinovyal sıvının; Hyaluronik Asit (HA) konsantrasyonu, molekül ağırlığı, viskoelastisitesi, şok emici ve lumbrikan özellikleri azalmıştır (1-3). Diğer yandan OA patogenezinde; proteolitik enzimlerin, reaktif oksijen radikallerinin ve lipid peroksidasyonunun hasar verici potansiyele sahip oldukları sinoviyal SIVı analizlerinde saptanmıştır $(4,5)$. Tedavisinde; farmakolojik, fizik-tedavi, eklem içi ve cerrahi tedavi seçenekleri bulunmaktadır. Bu seçenekler tek başına ya da kombinasyonlar şeklinde uygulanabilmektedir ve bu konuda rehberler geliştirilmiştir $(3,6,7)$.

Eklem içi HA enjeksiyonu; sinovyal sıvının elastisitesi ve viskozitesini normale döndürerek, koruma, kayganlaştırma ve şok emici etkisini arttırılabilir ve doku rejenerasyonuna katkı sağlanabilir (8). Artroskopik debridman ile debrisler, proteolitik enzimler ve enflamatuvar mediatörler eklemden uzaklaştırılabilir (9). Nutrisyonel antioksidan olan E vitamininin antioksidan etkiyle radikal aracılı patolojìi azaltabileceği, antienflamatuvar ve ağrıyı azaltıcı etkisi olduğu bildirilmektedir $(5,10,11)$. Dolayısıyla konservatif tedaviye yanıt alınamayan olgularda cerrahi, eklem içi ve antioksidan kombinasyonun OA tedavisinde etkili olabileceği düşünülebilir.

Bu çalışmada; konservatif tedaviyle semptomları iyileşmeyen diz $\mathrm{OA}^{\prime}$ Iı hastalarda artroskopik debridman ve sonrasında eklem içi HA ile birlikte peroral E vitamini tedavisinin klinik sonuçlarının etkili olup-olmadığını değerlendirmeyi amaçladık.

\section{Gereç ve Yöntem}

Kliniğimize diz ağrısı şikayeti ile başvuran, Amerikan Romatoloji Derneği'nin (3) kriterlerine göre klinik olarak diz OA tanısı konulmuş, en az üç ay konservatif tedaviye rağmen fayda görmeyen, ameliyat öncesi radyolojik değerlendirmede; yük vererek çekilen diz ön-arka, yan ve tanjansiyel patella grafilerinde Kellgren-Lawrence kriterlerine göre (12) evre II-III olan hastalar çalışmaya dahil edildi. Bilateral diz OA olan hastalarda ise şikâyetlerin fazla olduğu dizleri çalışmaya alındı. Sistemik sorgu ve fizik muayene sırasında: alerji hikayesi olan, son iki ay içinde oral veya intramüsküler kortikosteroid kullanmış olan, herhangi bir enfeksiyöz, enflamatuvar, metabolik vb. ağır sistemik hastalığı olan, çalışılan dize son üç ay içinde eklem içi tedavi uygulanan veya son 3 yıl içinde diz artroskopisi olan hastalar çalışmaya alınmadı. Takipleri düzenli yapılan ve çalışmayı tamamlayan 44 olgunun sonuçları değerlendirildi.

Yerel Etik Kurul onayı ve hasta onamları alındı. Çalışma tek kör, randomize ve kontrollü yapıldı. Bütün hastalara spinal anestezi altında artroskopik debridman yapıldı. Ameliyat sonrası hastalara; içinde sadece tedavi grup numarasının yazılı olduğu zarflar verilerek rastgele üç gruba ayrıldı: Birinci gruptaki (S) 14 hastaya; haftada bir 3 kez 2 ml eklem içi hylan G-F 20 (Synvisc ${ }^{\circledR}$ Genzyme Biosurgery, U.S) uygulandı. İkinci gruptaki (S+E) 15 hastaya; haftada bir, 3 kez 2 ml eklem içi hylan G-F 20 (Synvisc ${ }^{\circledR}$ Genzyme Biosurgery, U.S) ile birlikte 2 ay günde tek doz 400 iü oral vitamin E (Grandpherol ${ }^{\circledR}$ Sandoz, Türkiye) verildi. Üçüncü gruptaki (K) 15 hastaya ise; artroskopik debridman sonrası tedavi verilmedi ve kontrol grubu kabul edildi. Ameliyat sonrası bütün hastalara kompressif elastik bandaj, soğuk uygulama, aktif quadriceps egzersizleri ve sürekli pasif hareket programı uygulandı. Bütün hastalara günde 2 kez tiaprofenik asid (Surgam ${ }^{\circledR}$, Aventis, Türkiye) başlandı. Hastalar ortalama 3. günde ev egzersiz programıla taburcu edildi.

Tüm hastalar ameliyat öncesi, ameliyat sonrası 6. ve 12. aylarda ağrı, eklem sertliği ve fiziksel fonksiyon açısından Western Ontario ve McMaster Üniversiteleri Osteoartrit Indeksi (WOMAC) (13) ile değerlendirildi. Ayrıca, her muayenede sistemik ve lokal yan etkiler kaydedildi. Kontrol muayenelerinde hastaların değerlendirmelerini yapan hekim hangi hastanın, hangi tedaviyi aldığını bilmiyordu. Veriler SPSS 11.0 istatistik paket programı kullanarak değerlendirildi. İstatistiksel analizde Kruskal-Wallis Test ve Mann-Whitney $U$ testi kullanıldı. $\mathrm{p}<0,05$ farklıık anlamlı olarak kabul edildi.

\section{Bulgular}

Hastaların demografik özellikleri; yaş, vücut kitle indeksi (VKi) bakımından gruplar arası dağılım homojendi ve gruplar (grup S; $\mathrm{n}=14$, grup $\mathrm{S}+\mathrm{E} ; \mathrm{n}=15$ ve grup $\mathrm{K} ; \mathrm{n}=15$ ) arasında istatistiksel olarak anlamlı fark yoktu (Tablo 1).

Bütün gruplarda, ameliyat öncesi WOMAC skoruyla karşılaştırıldığında ameliyat sonrası 6.ve 12. aydaki skorlar azalmıştı. Bu artroskopik debridmandan hastaların fayda gördüğünü göstermektedir.

Ayrıca ameliyat öncesi, ameliyat sonrası 6. ve 12. ay WOMAC skorunda gruplar arasında anlamlı fark vardı (Tablo 2). Özellikle ameliyat öncesi WOMAC skorları bakımından gruplar arasında anlamlı fark olması nedeniyle ilk ve ikinci altı aylık dönemde WOMAC skorlarındaki farkın yani düzelmenin istatistiksel değerlendirilmesinin sonuçlarımızı daha objektif yansıtacağını düşünerek bu verileri değerlendirdik (Tablo 3 ve 4 ).

İlk altı aylık dönemde her iki tedavi grubunda da düzelme kontrol grubuna göre anlamlıydı (ameliyat öncesi-ameliyat sonrası 6. ay WOMAC skorlarının farkl; hem S+E grubunda hem de $S$ grubunda kontrol grubuna göre istatistiksel olarak anlamlıydı). Ancak tedavi grupları arasında (S+E ve S grupları) anlamlı fark yoktu (Tablo 3).

İkinci altı aylık dönemde her iki tedavi grubunda, düzelme kontrol grubuna göre anlamlı (ameliyat öncesi 6. ay-ameliyat sonrası 12. ay WOMAC skorlarının farkı; hem S+E grubunda hem de $S$ grubunda kontrol grubuna göre anlamlı) bulundu. Ayrıca tedavi grupları arasında ( $+\mathrm{E}$ ve $\mathrm{S}$ grupları) anlamlı fark vardı ve semptomları azaltmada $\mathrm{S}+\mathrm{E}$ grubu, $\mathrm{S}$ grubuna göre daha iyiydi (Tablo 4).

Bütün gruplardaki hastaların takiplerinde herhangi bir lokal ya da sistemik yan etkiye rastlanmadı.

\section{Tartışma}

Literatürde artroskopik debridman ve eklem içi HA tedavisi için uygun hasta seçimi vurgulanmış ve genelde hafif-orta derece diz OA'lı olgularda önerilmiştir. Hastaya, hastalığın ciddiyetine, takip süresine göre değişik sonuçlar rapor edilmiş ve çoğunlukla olumlu 
sonuçlar bildirilmiştir (14-16). Çalışmamızdaki hastalar klinik ve radyolojik olarak hafif-orta derece diz $\mathrm{OA}^{\prime}$ lı olgulardı ve yaş-VKi bakımından gruplar arasında anlamlı fark yoktu. Dolayısıyla bu çalışmada, literatürde belirtildiği gibi hasta seçimine dikkat edildiği söylenebilir. Ancak öncelikle belirtmek gerekir ki, bu çalışmanın bazı kısıtılıkları vardır. Tek başına eklem içi HA uygulanan grup olmadığı için ilgili literatür burada tartışılmamıştır. Tüm gruplara analjezik (Tiaprofenik asid) ve egzersiz tedavisi uygulanması sonuçlarımızı etkilemiş olabilir.

Uygun endikasyonda artroskopik debridman ile hastaların \%50-80'inde birkaç ay ile birkaç yıl arasında klinik iyileşme sağlandığı belirtilmektedir $(15,16)$. Clarke ve ark. $(15)$ artroskopik debridman ile diz osteoartritli hastaların \%66'sının orta dönemde yarar gördüğünü, Fond ve ark. (16) ise uygun hastalara artroskopik debridman ile beş yılda \%70 başarılı sonuç bildirmişlerdir. Diğer yandan; Moseley ve ark. (17) diz OA'lı 165 hastada yaptıkları kontrollü çalışmada; artroskopik debridman, artroskopik lavaj ve plasebo grupları arasında ağrıyı azaltma ve fonksiyonları iyileştirme bakımından anlamlı fark bulamamışlardır. Bu çalışmada; bütün gruplarda ameliyat öncesine göre ameliyat sonrası skorlarda görülen düzelme (Tablo 2) artroskopik debridmanın yararlı olduğunu bildiren literatürle uyumludur.

Artroskopik debridman ve HA uygulamasının sonuçlarının değerlendirildiği çalışmalarda: Listrat ve ark. (18) diz OA'lı 36 hastada yaptıkları kontrollü bir yıllık çalışmada, artroskopik debridman sonrası HA uyguladıkları grupta kontrol grubuna göre; yapısal parametrelerdeki bozulmanın ve analjezik kullanımının daha az, yaşam kalitesinin ise daha iyi olduğunu belirtmişlerdir. Vad ve ark. (19) kapalı lavaj ve bir hafta sonra eklem içi hylan G-F 20 uygulamasıyla sadece eklem içi hylan G-F 20 uygulanan olguları karşılaştırdıkları çalışmada, ortalama 13 aylık takip sonunda lavajla kombine edilmiş hylan G-F 20 grubunun sonuçlarının daha iyi

Tablo 1. Grupların yaş ve VKI ortalamaları.*

\begin{tabular}{lllll} 
& $\begin{array}{l}\text { Grup1 }(S) \\
(n=14)\end{array}$ & $\begin{array}{l}\text { Grup2 (S+E) } \\
(n=15)\end{array}$ & $\begin{array}{l}\text { Grup3 }(K) \\
(n=15)\end{array}$ & p değeri \\
\hline Yaş (yll) & $53,42 \pm 5,03$ & $53,46 \pm 7,14$ & $53,13 \pm 6,89$ & 0,980 \\
VKI $\left(\mathrm{kg} / \mathrm{m}^{2}\right)$ & $31,68 \pm 5,09$ & $30,86 \pm 3,70$ & $27,48 \pm 5,34$ & 0,081 \\
\hline *Kruskal-Wallis Test VKi: Vücut kitle indeksi
\end{tabular}

Tablo 2. WOMAC skorlarının gruplar arası karşılaştırıması.*

\begin{tabular}{|c|c|c|c|c|}
\hline & $\begin{array}{l}\text { Grup1 (S) } \\
(n=14)\end{array}$ & $\begin{array}{l}\text { Grup2 (S+E) } \\
(n=15)\end{array}$ & $\begin{array}{l}\text { Grup3 }(K) \\
(n=15)\end{array}$ & p değeri \\
\hline WMC AÖ & $100,28 \pm 9,91$ & $82,40 \pm 21,78$ & $70,73 \pm 21,24$ & 0,002 \\
\hline $\begin{array}{l}\text { WMC AS } \\
\text { 6. ay }\end{array}$ & $92,00 \pm 11,81$ & $73,33 \pm 18,67$ & $66,53 \pm 22,69$ & 0,003 \\
\hline $\begin{array}{l}\text { WMC AS } \\
\text { 12.ay }\end{array}$ & $85,92 \pm 10,71$ & $63,46 \pm 16,73$ & $63,86 \pm 20,61$ & 0,002 \\
\hline $\begin{array}{l}\text { *Kruskal-Walli } \\
\text { WMC AÖ: An } \\
\text { WMC AS } 6 . \text { a } \\
\text { WMC AS } 12 .\end{array}$ & $\begin{array}{l}\text { t } \\
\text { at öncesi WOMAC } \\
\text { neliyat sonrası } 6 \text {. } \\
\text { Ameliyat sonrası }\end{array}$ & $\begin{array}{l}\text { C skoru } \\
\text { ay WOMAC skoru } \\
\text { 12. ay WOMAC sk }\end{array}$ & & \\
\hline
\end{tabular}

olduğunu bildirmişlerdir. Heybeli ve ark. (20) evre 2-3 diz OA’ı 67 hastada yaptıkları prospektif, randomize kontrollü çalışmada, 24 haftalık takipte artroskopik debridman sonrası HA uygulanan grupta fonksiyon skorunda anlamlı düzelme olduğunu ancak ağrı skorunda anlamlı düzelme olmadığını bildirmişlerdir. Sonuç olarak artroskopi ve HA tedavi kombinasyonun erken dönemde yararlı olduğunu ancak uzun izlemli çalışmalar gerektiğini belirtmişlerdir. İzlem süresi daha uzun olan bir çalışmada ise; Atay ve ark. (14) evre 2-3 diz OA olan 45 hastanın 45 dizinde yaptıkları randomize kontrollü çalışmada; artroskopik debridman sonrası düşük ve yüksek molekül ağırlıklı eklem içi HA tedavisinin sonuçlarını bir yıl takip etmişler ve tedavi gruplarındaki hastaların WOMAC skorlarında anlamlı düzelme olduğunu bildirmişlerdir. Ancak tedavi grupları arasında fark olmadığını belirtmişlerdir. Sonuç olarak artroskopik debridmanın uygun endikasyonda yararlı bir tedavi yöntemi olduğu ve eklem içi HA tedavisiyle desteklenmesinin etkinliği daha da artıracağını bildirmişlerdir. Ayrıca artroskopik debridmanın OA semptomlarında rol oynayan patogenez mekanizmalarında değişikliklere neden olabileceği, dolayısıyla HA preparatlarının artroskopi yapılmamış dizlere göre etkisinde farklılıklar olabileceğini belirtmişlerdir.

Bu çalışmanın sonuçları (Tablo 3 ve 4) artroskopik debridman sonrası HA uygulamasının daha yararlı olduğunu bildiren literatürle uyumludur.

Diz OA'da eksojen E vitamininin yeri tartışmalıdır ve değişik sonuçlar bildirilmektedir. Deneysel bir çalışmada, Claassen ve ark. (21) in vitro kıkırdak kültürlerinde serbest oksijen radikalleri

Tablo 3. AÖ ile AS 6. aydaki ölçümlerin farklarının gruplar arasında karşılaştırılması. **

\begin{tabular}{llll} 
& Grup1 (S) & Grup2 (S+E) & p değeri \\
\hline WMC fark AÖ-AS 6. ay & $8,28 \pm 4,79$ & $9,06 \pm 6,73$ & 0,826 \\
& Grup1 (S) & Grup3 (K) & \\
WMC fark AÖ-AS 6. ay & $8,28 \pm 4,79$ & $4,20 \pm 3,94$ & 0,021 \\
WMC fark AÖ-AS 6. ay & Grup2 (S+E) & Grup3(K) & \\
& $9,06 \pm 6,73$ & $4,20 \pm 3,94$ & 0,020 \\
\hline
\end{tabular}

**Mann-WitneyU test

WMC fark AÖ-AS 6. ay: Ameliyat öncesi ile ameliyat sonrası 6.ayda WOMAC skorundaki fark

Tablo 4. AS 6. ay-AS 12. aydaki WOMAC skorlarının farklarının gruplar arasında karşılaştırılması.**

\begin{tabular}{llll} 
& Grup1 (S) & Grup2 (S+E) & p değeri \\
\hline WMC fark AS6-AS 12.ay & $6,07 \pm 3,49$ & $9,86 \pm 5,93$ & 0,040 \\
& Grup1(S) & Grup3(K) & \\
WMC fark AS6-AS 12.ay & $6,07 \pm 3,49$ & $2,66 \pm 3,41$ & 0,005 \\
& Grup2(S+E) & Grup3(K) & \\
WMC fark AS 6-AS 12.ay & $9,86 \pm 5,93$ & $2,66 \pm 3,41$ & 0,000 \\
\hline **Mann-WitneyU test & & & \\
$\begin{array}{l}\text { WMC fark AS 6-AS 12.ay: Ameliyat sonrası 6. ay-ameliyat sonrası 12. ayda WOMAC } \\
\text { skorundaki fark }\end{array}$
\end{tabular}


etkilerinin ortama $\mathrm{E}$ vitamini eklenmesi ile azaldığını göstermiş̧ir. Galleron ve ark. (22) ise tam tersine in vitro kıkırdak kültürlerinde serbest oksijen radikalleri etkilerinin ortama E vitamini eklenmesi ile etkilenmediğini rapor etmişlerdir. Jacquet ve ark. (23) diz ya da kalça osteoartritli 81 hastada yaptıkları prospektif, randomize, çift kör plasebo kontrollü çalışmada; E vitamini içeren gıda takviyesi alan grubun aldıkları analjezik miktarında azalma ve WOMAC skorlarında düzelme olduğunu sonuç olarak E vitamini gıda takviyesinin, analjezik ihtiyacını azaltacağını ve OA semptomlarını iyileştirebileceğini belirtmişlerdir. Haflah ve ark. (24) diz OA’lı 64 hastada yaptıkları çalışmada; vitamin $E$ ve glukozamin sülfat tedavisinin etkinliğini araştırmışlar, her iki grupta da WOMAC ve görsel analog skala skorlarında düzelme olduğunu ancak glukozamin sülfat grubunda serum malondialdehit düzeyinin, $\mathrm{E}$ vitamin grubunda ise serum $\mathrm{E}$ vitamin düzeyinin anlamlı derecede yüksek olduğunu bildirmişlerdir. Sonuç olarak günlük $400 \mathrm{mg} E$ vitamini tedavisini önerdiklerini ve bunun diz OA semptomlarını azaltmada potansiyel etkisi olduğunu belirtmişlerdir. Wang ve ark. (25) 293 sağlıklı yetişkinde farklı gıda takviyeleri ile yaptıkları çalışmada; 10 yıl sonunda hastalarda kıkırdak volümü, kemik alanı, kıkırdak defekti ve kemik iliği lezyonunu manyetik rezonans görüntüleme ile araştırmışlar. Diğer gruplarda kemik ya da kıkırdak volümünde etkisiz ya da azalma görülürken $\mathrm{E}$ vitamini alımının olumlu tibial plato kemik alanı ile ilişkili olduğunu bildirmişlerdir. Sonuçta; diyet değişikliklerinin OA patogenezinde ve tedavisinde rol oynayabileceğini belirtmişlerdir.

Diğer yandan Mc Alindon ve ark. (26) oral E vitamini takviyesinin diz OA semptomları ve ilerlemesini etkilemediğini bildirmektedirler. Wluka ve ark. (27) diz OA'lı 136 hastaya 500 iÜ/gün E vitamini vererek yaptıkları çalışmanın başında ve sonunda, tibial kıkırdak kalınlığını MR ile ölçmüşler ve $E$ vitamininin diz OA'da kıkırdak kalınlık kaybı ve semptomlarda etkisiz olduğunu bildirmişlerdir. Brand ve ark. (28) altı haftalık çift-kör, randomize ve plasebo kontrollü çalışmalarında $E$ vitamininin diz OA semptomlarını rahatlatmada etkisiz olduğunu bildirmişlerdir.

Bu çalışmanın sonuçları ilk altı dönemde cerrahi ve eklem içi tedaviye E vitamini eklenmesinin anlamlı etkisi olmadığını göstermektedir (Tablo 3). Ancak ikinci altı aylık dönemde; tedaviye E vitamini eklenmesinin semptomları azaltmada daha iyi olduğunu göstermektedir (Tablo 4). Bu sonuç diz OA'da E vitamini tedavisinin olumlu olduğunu bildiren çalışmalarla uyumlu olsa da özellikle daha yeni ve kanıt seviyesi daha yüksek olan çalışmalarda $E$ vitamininin diz $\mathrm{OA}^{\prime}$ da etkisiz olduğunu bildiren çalışmalarla çelişiyordu. Ancak yukarda bahsedilen çalışmalarda cerrahi ve/veya eklem içi tedavi almamış hastaların sonuçlarının bildirildiğini belirtmek gerekir.

Artroskopik debridman sonrası HA ve $E$ vitamini kombinasyonuyla ilgili randomize kontrollü bir çalışmada: Aydogan ve ark. (4) diz OA'ı 60 hastada; artroskopi sonrası hastaları dört gruba ayırmışlar; düşük-yüksek moleküllü ağırlıklı HA ve HA ile birlikte E vitamini tedavisini sadece artroskopi yapılan kontrol grubuyla karşılaştırmışlar. Tedavi öncesi ve sonrası kanda ve eklem sıvısında anti-oksidan enzim aktivitesi (süperoksit dismutaz, katalaz, glutatyon peroksidaz) ve lipid peroksidasyonu aktivitesi (malondialdehit) düzeylerini ölçmüşler. Anti-oksidan enzim aktivitesinde anlamlı değişiklik olmadığını ancak sinoviyal sıvıda malondialdehit seviyelerinin, kontrol grubu dışındaki bütün gruplarda tedavi öncesine göre anlamlı derecede azaldığını bununla birlikte gruplar arasında anlamlı fark olmadığını dolayısıyla E vitamini takviyesinin etkili olmayabileceğini belirtmişlerdir. Sonuçta; diz OA'da artroskopi sonrası HA tedavisinin sinoviyal sıvıda lipid peroksidasyonunu azalttığını bildirmişlerdir. Ancak belirtilen çalışmada hastaların klinik sonuçları araştırılmamıştır.

Belki de artroskopik debridman ve eklem içi HA tedavisiyle diz $\mathrm{OA}^{\prime}$ da: lipid peroksidasyonu ve oksidatif stres azaltılıyor, proteolitik enzimler ve enflamatuvar mediatörler uzaklaştırılıyor, sinovyal sıvının elastisitesi ve viskozitesinin normale dönmesiyle doku rejenerasyonu sağlanıyor olabilir $(4,8,9)$. Sonrasında ise E vitamini tedavisinin serbest oksijen radikallerini azaltmadaki antioksidan etkinliği daha da artıyor olabilir (29). Dolayısıyla bu tedavi kombinasyonu ile ağıı ve diğer semptomların etkili bir şekilde azaltılabilmesi olasıdır.

Sonuç olarak, diz OA'lı olgularda uygun endikasyonda artroskopik debridmanın yararlı olduğu, artroskopik debridman sonrası eklem içi HA uygulamasının tedavinin etkinliğini arttırabileceği, ayrıca oral E vitamini kombinasyonun diz OA semptomlarının hafifletilmesinde faydalı olabileceği kanısındayız.

\section{Çıkar Çatışması:}

Yazarlar herhangi bir çıkar çatışması bildirmemişlerdir.

\section{Kaynaklar}

1. Haq I, Murphy E, Dacre J. Osteoarthritis. Postgrad Med J 2003;79:377-83.

2. Sarban S, Satana T, Işıkan E. Diz osteoartritinde viskosuplementasyonun yeri. Aktüel Tıp Dergisi 2004;9:30-4.

3. Uysal GF, Başaran S. Diz Osteoartriti. Türk Fiz Tıp Rehab Derg 2009;Özel Sayı 1:1-7.

4. Aydogan NH, Baydar ML, Atay T, Perktas I, Baykal BY, Ozmeric A. The effect of arthroscopic surgery and intraarticular drug injection to the antioxidation system and lipid peroxidation at osteoarthritis of knee. Saudi Med J 2008;29:397-402.

5. Sutipornpalangkul W, Morales NP, Charoencholvanich K, Harnroongroj T. Lipid peroxidation, glutathione, vitamin $\mathrm{E}$, and antioxidant enzymes in synovial fluid from patients with osteoarthritis. Int J Rheum Dis 2009;12:324-8.

6. Recommendations for the medical management of osteoarthritis of the hip and knee. 2000 update. American College of Rheumatology Subcommittee on Osteoarthritis Guidelines. Arthritis Rheum 2000;43:1905-15.

7. Jordan KM, Arden NK, Doherty M, Bannwarth B, Bijlsma JW, Dieppe P, et al. EULAR Recommendations 2003: an evidence based approach to the management of knee osteoarthritis: Report of a Task Force of the Standing Committee for International Clinical Studies Including Therapeutic Trials (ESCISIT). Ann Rheum Dis 2003;62:145-55.

8. Wobig M, Bach G, Beks P, Dickhut A, Runzheimer J, Schwieger G, et al. The role of elastoviscosity in the efficacy of viscosupplementation for osteoarthritis of the knee: a comparison of hylan G-F 20 and a lowermolecular-weight hyaluronan. Clin Ther 1999;21:1549-62.

9. Dieppe P, Lim KKT. Osteoarthritis. In: Klippel JH, Dieppe PA, editors. Rheumatology. 2nd ed. Philadelphia: Mosby; 1998. p. 1-16.

10. Özgürsoy P. Osteoartritte tedavi ilkeleri. Romatizma 2006;21:67-72.

11. Blankenhorn G. Clinical effectiveness of Spondyvit (vitamin E) in activated arthroses. A multicenter placebo-controlled double-blind study. Z Orth Ihre Grenzgeb 1986;124:340-3.

12. Petersson IF, Boegard T, Saxne T, Silman AJ, Svensson B. Radiographic osteoarthritis of the knee classified by the Ahlback and Kellgren \& Lawrence systems for the tibiofemoral joint in people aged 35-54 years with chronic knee pain. Ann Rheum Dis 1997;56:493-6. 
13. Stratford PW, Kennedy DM, Woodhouse LI, Spadoni GF. Measurement properties of the WOMAC LK 3.1 pain scale. Ostearthritis Cartilage 2007; 15:266-72.

14. Atay T, Aslan A, Baydar ML, Ceylan B, Baykal B, Kırdemir V. Gonartrozlu hastalarda artroskopik debritman sonrası viskosuplemantasyon uygulamalarının karşılaştıııması. Acta Orthop Traumatol Turc 2008:4:228-33.

15. Clarke HD, Scott WN. The role of debridement: through small portals. J Arthroplasty 2003;18:10-3.

16. Fond J, Rodin D, Ahmad S, Nirschl RP. Arthroscopic debridement for the treatment of osteoarthritis of the knee: 2 and 5 year results. Arthroscopy 2002;18:829-34.

17. Moseley JB, O'Malley K, Petersen NJ, Menke TJ, Brody BA, Kuykendall $\mathrm{DH}$,et al. A controlled trial of arthroscopic surgery for osteoarthritis of the knee. N Engl Med 2002;347:81-88.

18. Listrat V, Ayral X, Patarnello F, Bonvarlet JP, Simonnet J, Amor B, et al. Arthroscopic evaluation of potential structure modifying activity of hyaluronan (Hyalgan) in osteoarthritis of the knee. Osteoarthritis Cartilage 1997;5:153-60.

19. Vad VB, Bhat AL, Sculco TP, Wickiewicz TL. Management of knee osteoarthritis: knee lavage combined with hylan versus hylan alone. Arch Phys Med Rehabil 2003;84:634-7.

20. Heybeli N, Doral MN, Atay OA, Leblebicioğlu G, Uzümcügil A. Intraarticular sodium hyaluronate injections after arthroscopic debridement for osteoarthritis of the knee: a prospective, randomized, controlled study. Acta Orthop Traumatol Turc 2008;42:221-7.

21. Claassen $H$, Schünke $M$, Kurz B. Estradiol protects cultured articular chondrocytes from oxygen-radical-induced damage. Cell Tissue Res 2005;319:439-45.
22. Galleron S, Borderie $D$, Ponteziere $C$, Lemarechal $H$, Jambou $M$, RochArveiller $\mathrm{M}$, et al. Reactive oxygen species induce apoptosis of synoviocytes in vitro. Alpha-tocopherol provides no protection. Cell Biol Int 1999:23:637-42.

23. Jacquet A, Girodet PO, Pariente A, Forest K, Mallet L, Moore N. Phytalgic, a food supplement, vs placebo in patients with osteoarthritis of the knee or hip: a randomised double-blind placebo-controlled clinical trial. Arthritis Res Ther 2009;11:R192.

24. Haflah NH, Jaarin K, Abdullah S, Omar M. Palm vitamin E and glucosamine sulphate in the treatment of osteoarthritis of the knee. Saudi Med J 2009;30:1432-8.

25. Wang Y, Hodge AM, Wluka AE, English DR, Giles GG, O'Sullivan R, et al. Effect of antioxidants on knee cartilage and bone in healthy, middle-aged subjects: a cross-sectional study. Arthritis Res Ther 2007;9:R66.

26. McAlindon TE, Jacques P, Zhang Y, Hannan MT, Aliabadi P, Weissman $B$, et al. Do antioxidant micronutrients protect against the development and progression of Knee osteoarthritis? Arthritis Rheum 1996;39:648-56.

27. Wluka AE, Stuckey S, Brand C, Cuttini FM. Supplementary vitamin E does not affect the loss of cartilage volume in knee osteoarthritis: a 2 year double blind randomized plesebo controoled study. I Rheumatol 2002;12:2585-91

28. Brand C, Snaddon J, Bailey M, Cicuttini F. Vitamin E is ineffective for symptomatic relief of knee osteoarthritis: a six month double blind, randomised, placebo controlled study. Ann Rheum Dis 2001;60:946-9.

29. Surapaneni KM, Ventkataramana G. Status of lipid peroxidation, glutathione, ascorbic acid, vitamin E and antioxidant enzymes in patients with osteoarthritis. Indian | Med Sci 2007;61:9-14. 